\title{
Granulocyte-specific antinuclear factors in synovial fluids and sera from patients with rheumatoid arthritis
}

\author{
ALLAN WIIK, ERIK JENSEN, AND JOHANNES FRIIS \\ From the Immunological Laboratory, Department of Infectious Diseases, Blegdamshospitalet, and the \\ Department of Rheumatology, Frederiksberg Hospital, Copenhagen, Denmark
}

The prevalence of antinuclear factors (ANF) found in sera and synovial fluids (SF) of patients with rheumatoid arthritis (RA) varies from one study to another, chiefly according to the technique used. The importance of sensitivity has been emphasized by Ritchie who found ANF in $89 \%$ of undiluted RA sera, employing rat liver as nuclear substrate and an antihuman immunoglobulin conjugate detecting the three main classes of immunoglobulins (Ig) (Ritchie, 1967). As $61 \%$ of normal control sera contained low titres of ANF $(<16)$ a titre of 16 was selected as the upper normal limit. Titres above 16 were found in $32 \%$ of the RA sera.

The choice of nuclear substrate is also important, since some ANF in RA show limited reactivity (Elling, Graudal, and Faber, 1968). Using human blood leucocytes and an antihuman Ig conjugate these authors found ANF reacting predominantly or solely with polymorphonuclear nuclei in $64 \%$ of RA sera and $62 \%$ of paired joint fluids. Previous cross absorption experiments on ANF positive RA and systemic lupus erythematosus sera using thyroid and leucocyte nuclei had shown the specificity of granulocyte-specific ANF (GS-ANF) (Elling, 1966). Such antibodies were thus detected in virtually all RA sera and about one-third of systemic lupus erythematosus sera.

Most authors have observed a lower incidence of ANF in rheumatoid SF than in sera (Barnett, Bienenstock, and Bloch, 1966; MacSween, Dalakos, Jasani, Boyle, Buchanan, and Goudie, 1968; Cracchiolo and Barnett, 1972; Munthe, 1972). On the other hand, ANF may be present in some SF when absent in the matched sera (Barnett and others, 1966; MacSween and others, 1968; Elling and others, 1968; Cracchiolo and Barnett, 1972; Munthe, 1972), perhaps indicating local production of ANF in the synovial membrane, in the same way as rheumatoid factors (Mellors, Heimer, Corcos, and Korngold, 1959; Hannestad and Mellbye, 1967).
The aim of this study was to evaluate a sensitive indirect immunofluorescence technique for determining prevalence and titres of GS-ANF and organnonspecific ANF (ON-ANF) in paired RA and osteoarthrosis (OA) sera and SF using both human leucocytes and thyroid as nuclear substrates, Ig class specific conjugates, and optical equipment giving close to optimal conditions for reading the results. The relative amounts of ANF were judged by titration of the samples.

\section{Materials and methods}

The patients were admitted to the department of rheumatic disease at Frederiksberg Hospital, Copenhagen. Healthy controls were blood donors from the transfusion service at Bispebjerg Hospital, Copenhagen and residents in an old people's home. The latter had no signs of acute or chronic diseases and their erythrocyte sedimentation rates and serum electrophoresis on paper were normal. The RA patients were classified according to the American Rheumatism Association (A.R.A.) criteria (Ropes, Bennett, Cobb, Jacox, and Jessar, 1959). Generally accepted criteria, including normal ESR and serum electrophoresis, were used for the diagnosis of OA. The age and sex distribution of patients and controls is recorded in Table $\mathbf{I}$. Patients were selected for arthrocentesis solely on the basis of sufficient SF being available.

SF were aspirated under sterile conditions into EDTA, the final concentration being about $0.01 \mathrm{mmol} / \mathrm{ml}$. A white cell and differential count was performed immediately. The fluid was centrifuged for 10 mins at $400 \times g$ and the supernatant incubated with testicular hyaluronidase (Penetrase ${ }^{\circledast}$, LEO, Copenhagen), $150 \mathrm{IU} / \mathrm{ml}$ SF for 30 mins at $+37^{\circ} \mathrm{C}$. The specimens were assayed for cryoproteins by overnight incubation at $+4^{\circ} \mathrm{C}$ followed by centrifugation for 10 mins at $1,000 \times g$. The supernatant fluids were stored at $-20^{\circ} \mathrm{C}$ until tested. The cryoprotein studies will be reported separately (Wiik, Jensen, Friis, and Bach-Andersen, in preparation).

Serum samples were obtained from all patients at the time of arthrocentesis. All sera and SF were coded and investigated without knowledge of diagnosis. 
Table I Patients and controls

\begin{tabular}{|c|c|c|c|c|}
\hline Diagnosis & $\begin{array}{l}\text { No. of } \\
\text { patients }\end{array}$ & $\begin{array}{l}\text { Age } \\
\text { (mean) }\end{array}$ & (range) & $\begin{array}{l}\text { Ratio } \\
M / F\end{array}$ \\
\hline $\begin{array}{l}\text { Classical RA } \\
\text { Definite RA } \\
\text { Probable RA } \\
\text { Possible RA } \\
\text { Osteoarthritis } \\
\text { Controls }\end{array}$ & $\begin{array}{r}43 \\
34 \\
6 \\
11 \\
24 \\
24\end{array}$ & $\begin{array}{l}65 \\
64 \\
53 \\
65 \\
74 \\
75\end{array}$ & $\begin{array}{l}36-81 \\
32-87 \\
24-71 \\
25-85 \\
37-88 \\
33-89\end{array}$ & $\begin{array}{l}10 / 33 \\
11 / 23 \\
2 / 4 \\
2 / 9 \\
9 / 15 \\
9 / 15\end{array}$ \\
\hline
\end{tabular}

SEROLOGICAL TESTS

Paired samples of sera and SF were tested for occurrence and titres of $\operatorname{IgG}, \operatorname{IgM}, \operatorname{IgA}$, and complement-fixing GS-ANF and ON-ANF by indirect immunofluorescence. 4-6 $\mu \mathrm{m}$ thick cryostat sections of human thyroid and smears of isolated and washed peripheral blood leucocytes from normal donors served as nuclear substrates (Wiik and Munthe, 1972). Sera were initially screened at $1 / 16$ in order to avoid detection of the low titres of ANF so common in normal individuals (Ritchie, 1967; A. Wiik, unpublished data), and the positive samples were titrated in doubling dilutions in phosphate buffered saline, pH 7·2.

A pilot study of about one-third of the SF showed four things. (1) The titres of ANF of all three Ig classes were generally lower in the SF than in the corresponding sera. (2) No prozone phenomena were seen. (3) IgG ANF in undiluted SF was only found in RA. (4) Hyaluronidase treatment did not affect ANF or rheumatoid factor titres. It was therefore decided to screen the rest of the SF undiluted and subsequently titrate the positive samples.

FITC-conjugated rabbit 'slow IgG' specific for human $\gamma$, $\mu$, and $\alpha$ chains and the $\beta_{1} \mathrm{C}$ component of human C3 were obtained from Dakopatts, Copenhagen. The specificity of the conjugates was confirmed by crossed immunoelectrophoresis (Laurell, 1965) and by performance tests on myeloma and macroglobulinaemia bone marrow samples as described before (Wiik and Munthe, 1972). The fluorescein/protein ratio, estimated as OD 495/OD 278 (The and Feltkamp, 1970) was in all cases around 0.6, the staining titres $2,000-4,000$, and the plateau end point titres 64-128 using a laboratory standard ANF positive serum at dilution 1/10 (Beutner, Sepulveda, and Barnett, 1968). No nonspecific staining was seen even at low dilutions of the conjugates. A working dilution of $1 / 25$ was chosen for all conjugates.

Inactivated specimens of sera and SF were tested for rheumatoid factors by the latex fixation slide test $\mathbf{~} \mathrm{Hy}$ land). Sera were also tested by the sheep cell agglutination method. Sera containing rheumatoid factors in titres $\geqslant 32$ by the latex fixation test and/or titres $\geqslant 20$ by the Waaler-Rose test were considered seropositive.

\section{MICROSCOPY}

All FITC-stained preparations were read in a Leitz Orthoplan microscope equipped for incident light illumination (Ploem, 1967) using an HBO 200 mercury lamp as light source, a 4 mm BG 38 glass filter, two KP 490 interference filters, and a TK $\mathbf{4 8 5}$ dichroic mirror for selection of excitation light; a $1.5 \mathrm{~mm} 530 \mathrm{~nm}$ glass filter was the barrier filter. This arrangement allows a broad spectrum of light to pass from the light source to the object giving very brilliant fluorescence of FITC and an only just visible background showing the outlines of the unstained preparation. In any case of doubt as to the distinction between autofluorescence and specific fluorescence the two KP 490 interference filters and the $530 \mathrm{~nm}$ secondary filter were exchanged for two AL 470 narrow band interference filters and a $1.5 \mathrm{~mm} 510 \mathrm{~nm}$ glass filter, respectively. This combination gave a bright though somewhat diminished FITC-fluorescence, contrasting with a black background.

\section{IMMUNOCHEMICAL METHODS}

IgG, IgM, and IgA concentrations in sera and SF were determined by Laurell's quantitative immunoelectrophoresis as modified by Weeke (Weeke, 1968).

DEFINITIONS AND NOMENCLATURE

GS-ANF are antibodies capable of reacting with nuclei of mature neutrophilic and eosinophilic granulocytes and monocytes in vitro, but not with lymphocytes or other cell nuclei, in this report represented by human thyroid nuclei.

ANF are designated as granulocyte-specific if they are found as the only detectable ANF in the specimen or if the specific reaction is seen at least two dilution steps higher than the lymphocyte and/or thyroid nuclear reaction. Conversely ANF are called organ-nonspecific if the lymphocyte and/or thyroid reactivity continues to the highest positive dilution of the specimen or at least two dilution steps lower than the granulocyte-specific reaction.

The rationale for this is that granulocytes seem to contain most of the nuclear antigens found in other human cells, but in addition specific antigens (Elling, 1966). Therefore, GS-ANF occurring in titres equal to or lower than ON-ANF cannot be identified by dilution only, as ON-ANF also react with granulocyte nuclei. Consequently, the values for GS-ANF are minimum estimates.

\section{Results}

In sera from classical and definite cases of RA, significant titres of IgG ANF (i.e. titres $\geqslant 16$ ) were found in $85.9 \%$, the majority being GS-ANF (Table II). The prevalence of IgG GS-ANF was higher in seropositive than in seronegative cases $(P<0.05)$, but for IgG ON-ANF it was the same. IgM and IgA ANF were seen with equal frequency in seropositive and seronegative cases.

When patients with RA were listed according to the A.R.A. criteria the trend of prevalence of IgG ANF fell accordingly (Table III). 
Table II Prevalence of IgG GS- and $O N-A N F$ in $R A^{*}$ sera (titres $\geqslant 16$ )

\begin{tabular}{|c|c|c|c|c|c|c|c|}
\hline Diagnosis & $\begin{array}{l}\text { No. of } \\
\text { specimens }\end{array}$ & $\begin{array}{l}\operatorname{IgG} \\
\text { (no.) }\end{array}$ & $\begin{array}{l}A N F \\
(\%)\end{array}$ & $\begin{array}{l}\operatorname{IgG} \\
\text { (no.) }\end{array}$ & $\begin{array}{l}G S-A N F \\
(\%)\end{array}$ & $\begin{array}{l}\operatorname{IgG} \\
\text { (no.) }\end{array}$ & $\begin{array}{l}O N-A N F \\
(\%)\end{array}$ \\
\hline $\begin{array}{l}\text { Seropositive RA } \\
\text { Seronegative RA }\end{array}$ & $\begin{array}{l}61 \\
24\end{array}$ & $\begin{array}{l}56 \\
17\end{array}$ & $\begin{array}{l}91 \cdot 8 \\
70 \cdot 8\end{array}$ & $\begin{array}{l}49 \\
14\end{array}$ & $\begin{array}{l}80 \cdot 3 \\
58 \cdot 3\end{array}$ & $\begin{array}{r}19 \\
8\end{array}$ & $\begin{array}{l}31 \cdot 1 \\
33 \cdot 3\end{array}$ \\
\hline All RA & 85 & 73 & 85.9 & 63 & $74 \cdot 1$ & 27 & $31 \cdot 8$ \\
\hline
\end{tabular}

- Classical and definite RA.

Table III Prevalence of IgG GS- and ON-ANF in sera from RA patients classified according to the A.R.A. criteria

\begin{tabular}{|c|c|c|c|c|c|c|c|}
\hline Diagnosis & $\begin{array}{l}\text { No.of } \\
\text { specimens }\end{array}$ & $\begin{array}{l}\operatorname{Ig} G \\
\text { (no.) }\end{array}$ & $\begin{array}{l}A N F \\
(\%)\end{array}$ & $\begin{array}{l}\operatorname{Ig} G \\
\text { (no.) }\end{array}$ & $\begin{array}{l}\text { GS-ANF } \\
(\%)\end{array}$ & $\begin{array}{l}\operatorname{IgG} \\
\text { (no.) }\end{array}$ & $\begin{array}{l}O N-A N F \\
(\%)\end{array}$ \\
\hline $\begin{array}{l}\text { Classical RA } \\
\text { Definite RA } \\
\text { Probable RA } \\
\text { Possible RA }\end{array}$ & $\begin{array}{r}46 \\
39 \\
7 \\
12\end{array}$ & $\begin{array}{r}41 \\
32 \\
4 \\
4\end{array}$ & $\begin{array}{l}89 \cdot 1 \\
82 \cdot 1 \\
57 \cdot 1 \\
33 \cdot 3\end{array}$ & $\begin{array}{r}36 \\
27 \\
1 \\
3\end{array}$ & $\begin{array}{l}78 \cdot 3 \\
69 \cdot 2 \\
14 \cdot 3 \\
25 \cdot 0\end{array}$ & $\begin{array}{r}15 \\
12 \\
3 \\
2\end{array}$ & $\begin{array}{l}32 \cdot 6 \\
30 \cdot 8 \\
42 \cdot 8 \\
16 \cdot 7\end{array}$ \\
\hline
\end{tabular}

Comparison was also made between patients with classical and definite RA (henceforth called RA) and OA (Figs 1 and 2). A highly significant difference was found for IgG GS-ANF (P < 0.0001), and for IgG ON-ANF the difference was also significant, but less conspicuously so $(P<0.025)$. IgM GS-ANF was commoner in RA than in OA $(P<0.05)$, but IgM ON-ANF and IgA GS- and ON-ANF occurred in similar incidence. Figs 2 and 3 show that OA patients do not differ from healthy controls.

The prevalence of IgG, IgM, and IgA ANF in undiluted SF almost exactly corresponded to the values given for RA and OA sera at dilution 1/16 in Figs 1 and 2. In summary, IgG ANF was detected in $82.3 \%$ of the RA SF but in only $20 \%$ of the OA SF. Granulocyte specificity was predominant in the former, being found in $69.4 \%$. IgM and IgA ANF w:re of little help in distinguishing between RA and OA SF.

In 68 paired sera and SF from RA patients comparison was made between the titres of IgG GS-ANF in the two specimens. Patients exhibiting positive reactions in the SF but not in the serum at screening dilution $(1 / 16)$ were checked for lower titres of ANF in serum (Fig. 4). When a standard technical error of one dilution step in each direction is taken into account, only five patients had significantly higher titres of IgG GS-ANF in the SF than in the corresponding serum. The reverse situation was seen in thirty-six patients, eleven of whom had no detectable IgG GS-ANF in the SF. In all RA specimen pairs containing IgG ON-ANF, titres were compared (Fig. 5). The SF titres surpassed the serum titres in 8 cases, 4 of these having no antibody in the serum. In

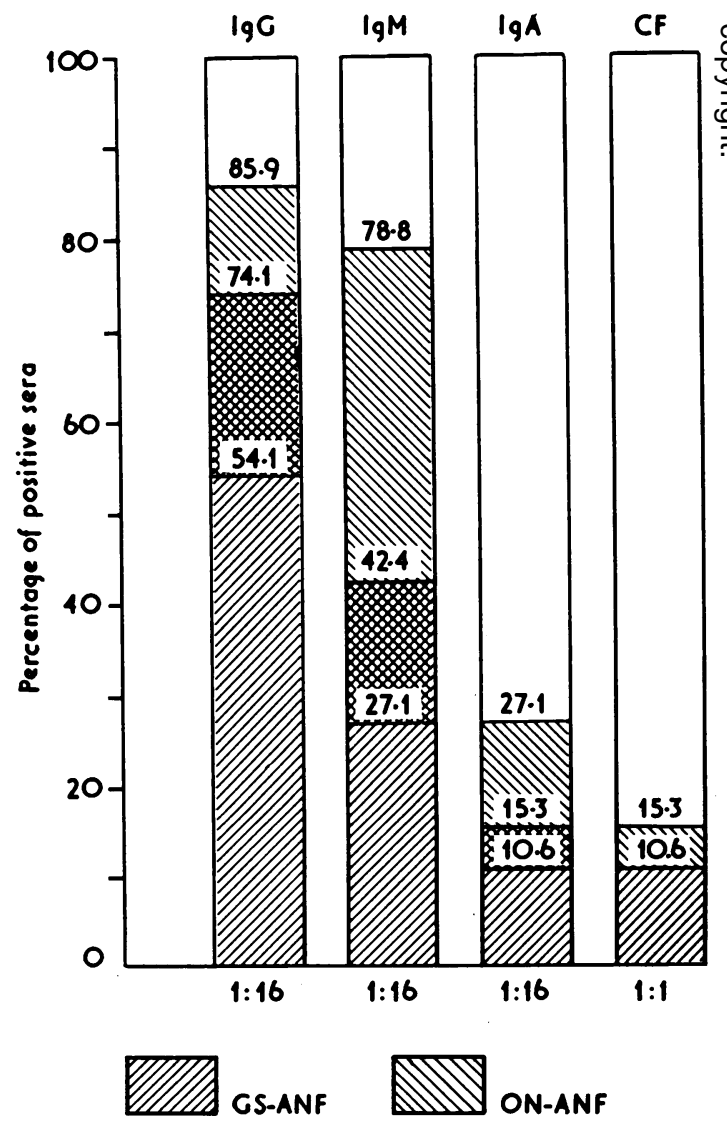

FIG. 1 Prevalence of $\operatorname{IgG}, \operatorname{IgM}, \operatorname{Ig} A$, and complementfixing (CF) $G S$ - and $O N-A N F$ in $R A$ sera 

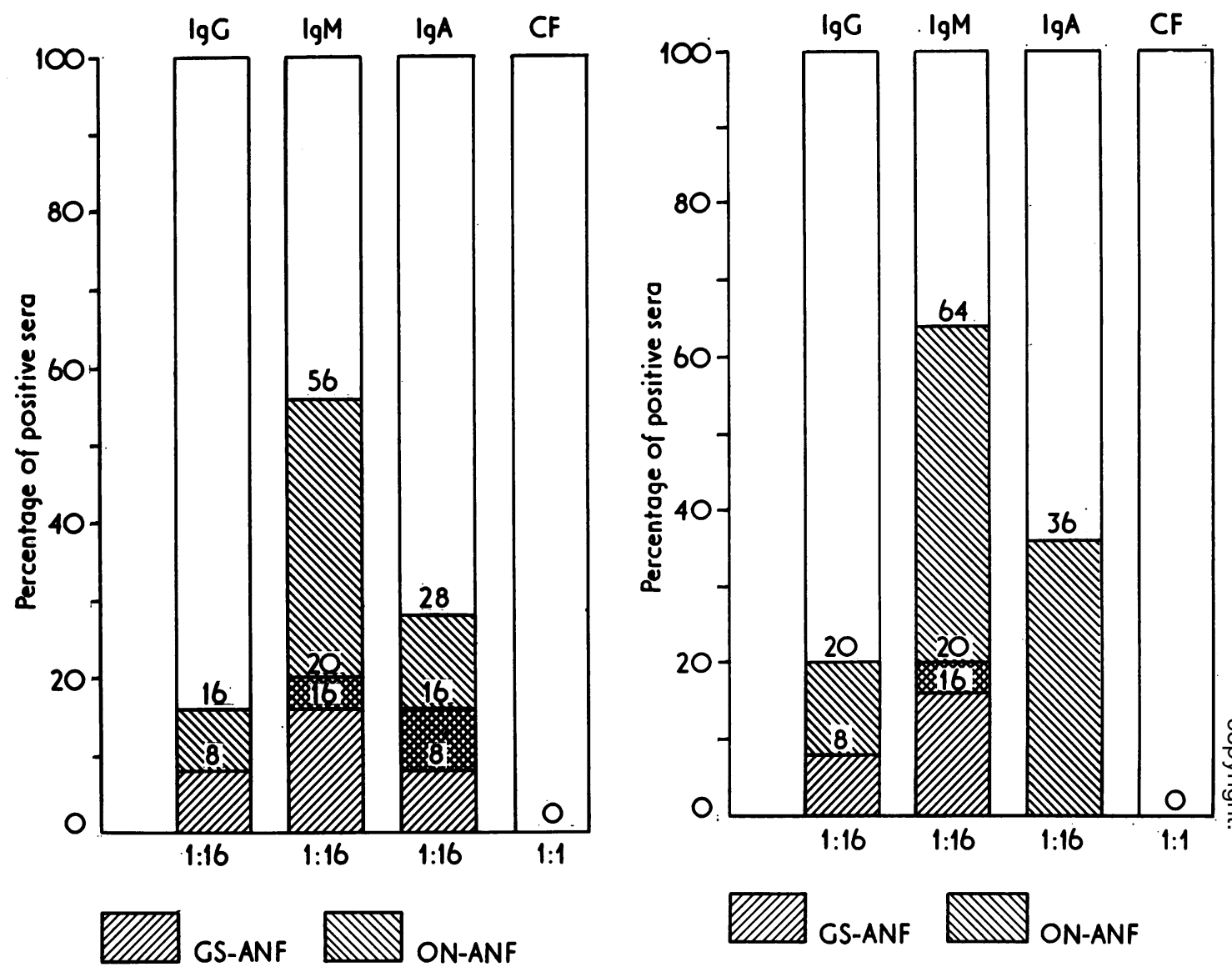

FIG. 2 Prevalence of $\operatorname{IgG}, \operatorname{IgM}, \operatorname{IgA}$, and complementfixing (CF) GS- and ON-ANF in osteoarthrosis sera

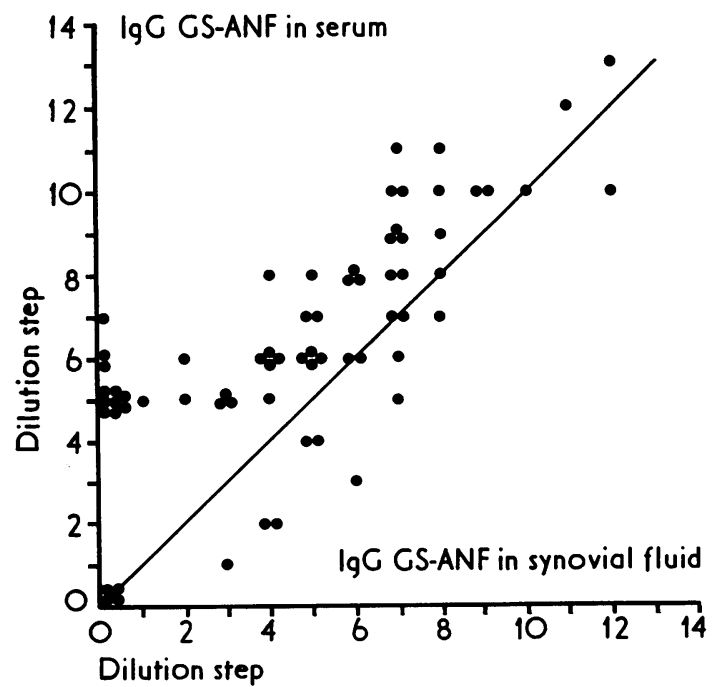

FIG. 4 Relation between titres of IgG GS-ANF in paired sera and synovial fluid from $R A$ patients (see text)

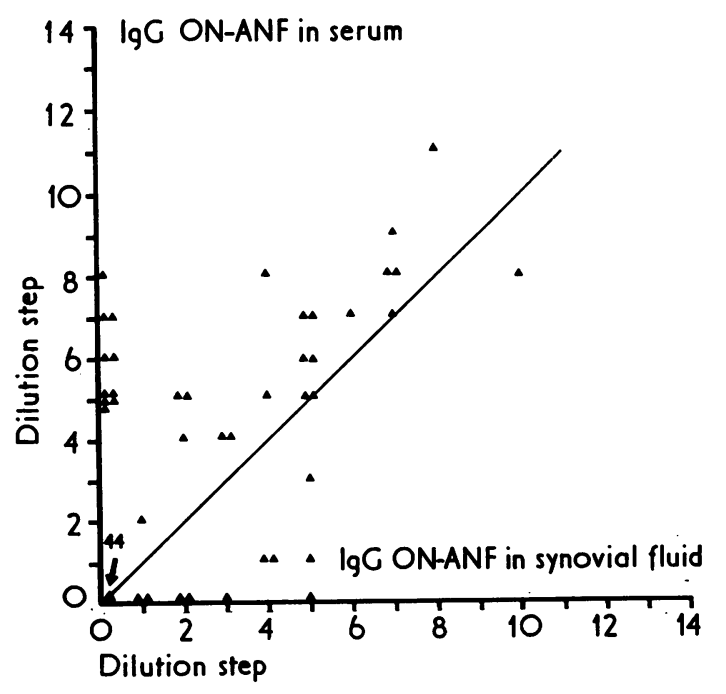

FIG. 3 Prevalence of $\operatorname{IgG}, \operatorname{IgM}, \operatorname{IgA}$, and complementfixing $(C F) G S$ - and $O N-A N F$ in healthy control sera

FIG. 5 Relation between titres of IgG ON-ANF in paired sera and synovial fluid in $R A$ patients (see text) 
Table IV Comparison between ANF titres in paired $R A$ sera and synovial fluids (no. of paired specimens)

\begin{tabular}{|c|c|c|c|c|c|c|c|c|}
\hline ANF titre relations & $I g M$ & $G S-A N F$ & $I g M$ & $O N-A N F$ & $\operatorname{Ig} A$ & $G S-A N F$ & $\operatorname{Ig} A$ & $O N-A N F$ \\
\hline $\begin{array}{l}\text { Serum < SF* } \\
\text { Serum }>\text { SF }^{*} \\
\text { Serum = SF } \\
\text { Both negative }\end{array}$ & $\begin{array}{r}4 \\
15\end{array}$ & $\begin{array}{l}4 \dagger \\
5 \ddagger\end{array}$ & $\begin{array}{r}4 \\
28\end{array}$ & $20^{11 \ddagger}$ & $\begin{array}{r}6 \\
12\end{array}$ & $6^{6}{ }^{10 \dagger}$ & $\begin{array}{r}3 \\
15\end{array}$ & ${ }^{14} \underbrace{10 \dagger}$ \\
\hline Total & & & & 85 & & 61 & & 85 \\
\hline
\end{tabular}

- Titre difference $\geqslant$ two dilution steps.

Serum negative.

I SF negative.

contrast, eighteen patients showed a surplus of detectable IgG ON-ANF in the serum, ten of these lacking such antibodies in the SF. Similar comparisons were made of titres of IgM and IgA GS-ANF and ON-ANF in paired RA sera and SF (Table IV).

Table $\mathrm{V}$ Ig class nature of GS-ANF surplus in $R A$ synovial fluids (titre difference $\geqslant 2$ dilution steps)

\begin{tabular}{llll}
$\begin{array}{l}\text { No. of } \\
\text { paired } \\
\text { specimens (16) }\end{array}$ & IgG & IgM & IgA \\
\cline { 3 - 4 } 4 & + & - & - \\
6 & - & + & - \\
4 & - & - & + \\
0 & + & + & - \\
1 & + & + & + \\
1 & + & + & + \\
0 & + & & +
\end{tabular}

Table VI Ig class of $O N$-ANF surplus in $R A$ synovial fluids (titre difference $\geqslant 2$ dilution steps)

\begin{tabular}{llll}
$\begin{array}{l}\text { No. of } \\
\text { paired } \\
\text { specimens (16) }\end{array}$ & IgG & IgM & IgA \\
\cline { 3 - 4 } \cline { 3 - 4 } 8 & + & - & - \\
4 & - & + & - \\
3 & - & - & + \\
1 & + & + & - \\
0 & + & + & + \\
0 & + & + & + \\
0 & + & + & + \\
\hline
\end{tabular}

It is clear that the majority of pairs giving positive reactions in one or both samples had serum titres comparable to or exceeding those in the SF, and only a minority showed the reverse. In summary, these were sixteen patients with an SF surplus of GS-ANF in at least one Ig class, the surplus in fourteen being restricted to one Ig class (Table V). The same is true for ON-ANF, the SF surplus occurring in only one Ig class in fifteen of sixteen patients (Table VI). Table VII shows that ANF titres did not reflect the distribution of total IgG, IgM, and IgA in sera and SF. Surplus ANF or rheumatoid factors in SF of RA patients were not especially characteristic of early disease (Table VIII).

A trend towards inverse correlation was shown between titres of IgG GS-ANF in SF and the number of polymorphonuclear granulocytes (Fig. 6).

Table VIII Presence of surplus $A N F$ and/or rheumatoid factors in SF of RA patients with early* and longstanding $\dagger$ disease

\begin{tabular}{|c|c|c|}
\hline \multirow{2}{*}{$\begin{array}{l}\text { Synovial fluid } \\
\text { surplus of }\end{array}$} & \multicolumn{2}{|c|}{ Disease duration } \\
\hline & $<1$ year & $>10$ years \\
\hline $\begin{array}{l}\text { IgG ANF } \\
\text { IgM ANF } \\
\text { IgA ANF } \\
\text { Rheumatoid }\end{array}$ & $\begin{array}{l}3 / 15(20.0 \%) \\
2 / 15(13 \cdot 3 \%) \\
1 / 15(6.7 \%)\end{array}$ & $\begin{array}{l}2 / 34(5.9 \%) \\
4 / 34(11.8 \%) \\
4 / 34(11.8 \%)\end{array}$ \\
\hline factors $\ddagger$ & $6 / 15(40 \cdot 0 \%)$ & $10 / 34(29 \cdot 4 \%)$ \\
\hline
\end{tabular}

Table VII Demonstrable serum and synovial fluid content of $\operatorname{IgG}, \operatorname{IgM}$, and $\operatorname{Ig} A G S-A N F$ (Case 1 ) and ON$A N F$ (Case 2) in two RA patients compared with total amounts of $\operatorname{IgG}, \operatorname{Ig} M$, and $\operatorname{Ig} A$ (in brackets) in $g / l$.

\begin{tabular}{|c|c|c|c|}
\hline Case no. & $\begin{array}{l}\operatorname{Ig} G G S-A N F \\
\text { serum } / S F\end{array}$ & $\begin{array}{l}\operatorname{Ig} M G S-A N F \\
\text { serum } / S F\end{array}$ & $\begin{array}{l}\operatorname{Ig} A G S-A N F \\
\text { serum } / S F\end{array}$ \\
\hline \multirow[t]{2}{*}{1} & $\begin{array}{l}64 / 512 \\
(14 \cdot 1 / 10 \cdot 2 \mathrm{~g} / 1 .)\end{array}$ & $\begin{array}{l}16 / 0 \\
(1 \cdot 41 / 0 \cdot 31 \mathrm{~g} / 1 .)\end{array}$ & $\begin{array}{l}16 / 16 \\
(1.95 / 1.66 \mathrm{~g} / 1 .)\end{array}$ \\
\hline & $\begin{array}{l}\operatorname{IgG} O N-A N F \\
\text { serum } / S F\end{array}$ & $\begin{array}{l}\operatorname{IgM} O N-A N F \\
\text { serum } / S F\end{array}$ & $\begin{array}{l}\operatorname{IgA} O N-A N F \\
\text { serum/SF }\end{array}$ \\
\hline 2 & $\begin{array}{l}1 / 8 \\
(12 \cdot 9 / 8 \cdot 7 \mathrm{~g} / 1 .)\end{array}$ & $\begin{array}{l}32 / 32 \\
(0 \cdot 43 / 0 \cdot 24 g / 1 .)\end{array}$ & $\begin{array}{l}8 / 0 \\
(1 \cdot 46 / 0.89 \mathrm{~g} / 1 .)\end{array}$ \\
\hline
\end{tabular}




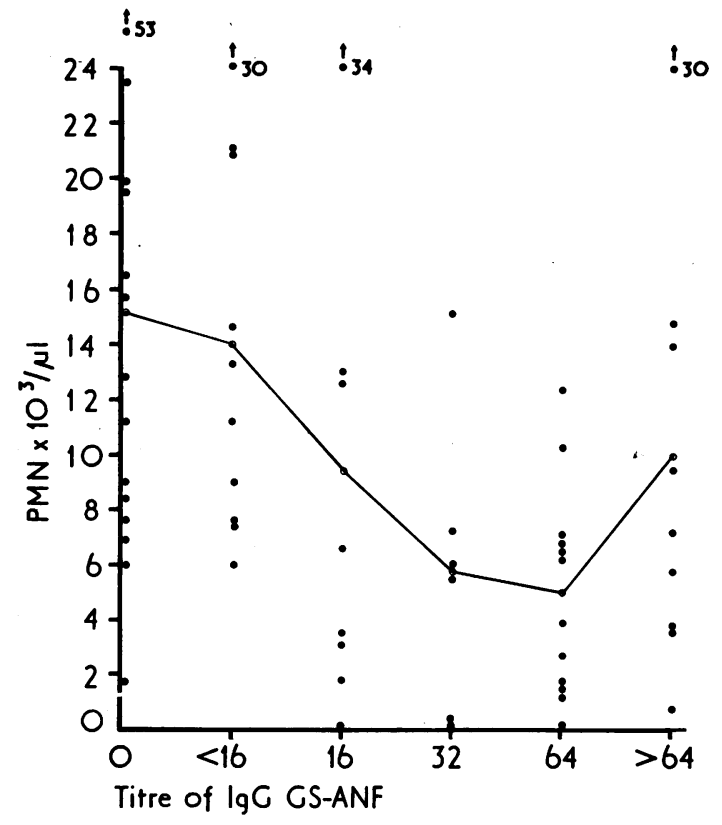

FIG. 6 Relation between the number of polymorphonuclear granulocytes $(P M N)$ and the titre of IgG GS-ANF in $59 R A$ synovial fluids. Each shows the findings in one patient. $\bigcirc$ represents the calculated mean number of neutrophils

\section{Discussion}

The incidence of ANF in matched sera and SF varies considerably even in more recent reports. Many factors may influence the results. Among the more important are the nuclear substrate, the dilution of the specimens investigated, the specificity and quality of the conjugates used and the optical equipment employed. The selection of patients has been more uniform, being mainly based on availability of sufficient SF for study.

We have chosen human leucocytes and thyroid sections as nuclear substrates, the former to detect both the GS-ANF and the ON-ANF, the latter to confirm the specificity of the antibodies. A preliminary study of normal blood donor sera showed a high prevalence of ANF of the IgM class even at dilution 1/16 whereas IgG ANF occurred in about $15 \%$ of undiluted normal sera, but in only $2 \%$ of the sera at dilution 1/16 (A. Wiik, in preparation). This dilution was chosen for the present study of patient sera. The conjugates used were prepared from 'slow IgG' fractions of rabbit antisera, which contain more than $90 \%$ of the precipitins, and are the most suited to labelling (Brooks, Lewis, and Pittman, 1965). The mean degrees of conjugation (The and Feltkamp, 1970 ) of the final products was close to 2 after DEAE chromatography. They gave no nonspecific fluorescence even at low dilutions. The optical detector system was equipped with interference filters which allowed close to maximum transmission of the desired wavelengths of excitation light to the object and at the same time took advantage of the epiillumination principle (Ploem, 1967).

The present study confirms the strong correlation between the presence of ANF in serum and paired SF (MacSween and others, 1968; Elling and others, 1968; Cracchiolo and Barnett, 1972).

IgG ANF in titres $\geqslant 16$ seemed to be very characteristic constituents of RA sera and SF (see Fig. 1), the prevalence increasing with the level of certainty of the diagnosis according to the A.R.A. criteria. IgG ANF discriminated fairly well between RA and OA specimens, whereas IgM and IgA ANF did not. In accordance with earlier studies complement-fixing ANF were rare in RA sera (Wiik and Munthe, 1972), and also rare in SF. The incidence of IgG, IgM, and IgA ANF in OA sera correspond closely to that of age and sex matched controls. Earlier data indicate that ANF occurs with increasing frequency in older persons, expecially women (Svec and Veit, 1967; Willkens, Whitaker, Anderson, and Berven, 1967). Accordingly the rather high prevalence of ANF in the controls and the OA patients can probably be ascribed to their age and sex.

GS-ANF are common in RA sera and SF (Elling and others, 1968; Wiik, Jensen, and Friis, 1973). The present study confirms this, GS-ANF constituting the vast majority of the IgG ANF population and also occurring in IgM and IgA. IgG GS-ANF were more frequent in seropositive than in seronegative cases, but there was no correlation between the titres of these antibodies and those of rheumatoid factors detected by the RA latex fixation test (correlation coefficient $r=0.29$ ).

Several authors have reported discrepancies between the presence of ANF in sera and SF. Thus ANF have been shown in the serum but not in the matched SF in 30\% (MacSween and others, 1968), $19 \%$ (Cracchiolo and Barnett, 1972), and 13\% (Elling and others, 1968), respectively. ANF has been found in the SF but not in the corresponding serum in $17 \%$ (Cracchiolo and Barnett, 1972; Elling and others, 1968) and in 12\% (MacSween and others, 1968; Munthe, 1972). In our study the titres of ANF in RA sera clearly exceeded those of SF in some of the patients. This may indicate blocking of ANF by free nuclear antigens in SF (Barnett, 1968), or removal of the ANF by cryoprecipitation (Cracchiolo, Goldberg, Barnett, and Bluestone, 1971). However, ANF may participate in different forms of immune complexes in serum and SF, the Ig class of ANF being masked by antibodies of other Ig classes such as antiglobulins or immunoconglutinins. Comparisons between serum and SF ANF titres may thus in this respect be meaningless. This view is supported by the data in Tables V, VI, and VII, where the apparent surplus of 
GS-ANF and ON-ANF was mostly restricted to only one Ig class, other Ig classes of ANF being present in comparable or even significantly higher titres in the serum. Evidence for local production or trapping of ANF in the synovium is thus still lacking.

The inverse correlation found between the number of neutrophils and the titres of IgG GS-ANF may indicate binding of GS-ANF by free nuclear antigens, removal of GS-ANF by phagocytosis or even some kind of autoaggressive effect of the GS-ANF towards target cells through yet unknown mechanisms.

Comparison of isologous reacting rheumatoid factors in paired sera and SF has been avoided here, since IgG aggregates, which may be found in RA SF (Hannestad, 1967; Winchester, Agnello, and Kunkel, 1970) as well as in RA sera (Kunkel, Müller-Eberhard, Fudenberg, and Tomasi, 1961; Schrohenloher, 1966; Winchester, Kunkel, and Agnello, 1971), can cause partial or complete blocking of rheumatoid factor reactions (Hannestad, 1967) when particle agglutination systems are used.

It has been suggested that the presence of significant amounts of rheumatoid factors in SF but not in serum could be characteristic of early RA (Cracchiolo and Barnett, 1972). In two cases of early RA these authors also found ANF in SF but not in serum. In our study a significant surplus of rheumatoid factors and/or ANF was found in both patients with early RA (less than 1 year duration) and longstanding cases (more than 10 years duration).

\section{Summary}

This study was undertaken to evaluate the efficiency of a sensitive indirect immunofluorescence technique for determining the prevalence and titres of IgG, IgM, and IgA granulocyte-specific antinuclear factors (GS-ANF) and organ-nonspecific antinuclear factors (ON-ANF) in 85 paired sera and SF from patients with classical and definite RA and 24 paired speci- mens from patients with OA. The predominant ANF found in RA specimens was IgG GS-ANF, which occurred in $74.1 \%$ of the sera in titres of 16 or more and in $69.4 \%$ of the undiluted SF. Similar titres of IgG ON-ANF were found in $31.8 \%$ of the sera and $36.5 \%$ of the SF. The serum titres were most often comparable to or higher than those of the paired SF, but in some cases the SF titres clearly exceeded the serum titres, perhaps reflecting a local production of ANF in the inflamed synovium. The apparent SF surplus of both GS-ANF and ON-ANF was mostly restricted to one Ig class although at least two Ig classes of specific antibodies were detected in both serum and SF in all specimen pairs. This may be due to the participation of ANF in different forms of immune complexes in sera and SF, one Ig class of ANF being sometimes masked by other Ig classes of antibodies known to participate in immune complexes, as with antiglobulins and immunoconglutinins. In contrast with RA specimens, IgG GS-ANF and ON-ANF were infrequent in OA sera and SF and in normal control sera, although IgM and IgA GS-ANF and ON-ANF were very common in all three groups. An inverse correlation was seen between the numbers of polymorphonuclear granulocytes and the titres of IgG GS-ANF in RA SF. In differentiating between RA and OA we propose the use of diluted sera and undiluted SF for IgG ANF and both human washed leucocytes and another nuclear substrate to detect both the GS-ANF and the ON-ANF. The incident light illumination system is available for reading the results.

We express our gratitude to Professor Viggo Faber for helpful advice and criticism, and to Mrs. Tove Dietz, Mrs. Merete Skånild, Miss Åse Stricker-Nielsen, and Mrs. Hanne Sørensen for skilful technical assistance. This study was supported by the National Danish Association Against Rheumatic Diseases, The National Danish Research Council, the Hindsgaul Foundation, and the NOVO Foundation.

\section{References}

BARNETT, E. V. (1968) Arthr. and Rheum., 11, 407 (Detection of nuclear antigens (DNA) in normal and pathologic human fluids by quantitative complement fixation) , Bienenstock, J., AND BLOCH, K. J. (1966) J. Amer. med. Ass., 198, 143 (Antinuclear factors in synovia)

Beutner, E. H., Sepulveda, M. R., AND Barnett, E. V. (1968) Bull. Wld. Hlth. Org., 39, 587 (Quantitative studies of immunofluorescent staining. Relationships of characteristics of unabsorbed antihuman IgG conjugates to their specific and non-specific staining properties in an indirect test for antinuclear factors)

Brooks, J. B., Lewis, V. J., ANd Pittman, B. (1965) Proc. Soc. exp. Biol. (N.Y.), 119, 748 (Separation of fluorescent antibody conjugates into $7 \mathrm{~S}$ and $19 \mathrm{~S}$ globulin components by gel filtration)

Cracchiolo, A., III, and Barnett, E. V. (1972) J. Bone Jt Surg., 54A, 828 (The role of immunological tests in routine synovial fluid analysis)

—, Goldberg, L. S., BARnetT, E. V., AND Bluestone, R. (1971) Immunology, 20, 1067 (Studies of cryoprecipitates from synovial fluid of rheumatoid patients)

Elling, P. (1966) Acta path. microbiol. scand., 68, 281 (Reaction of antinuclear factors with polymorphonuclear leucocytes. I. Absorption studies)

-, Graudal, H., AND FABer, V. (1968) Ann. rheum. Dis., 27, 225 (Granulocyte-specific antinuclear factors in serum and synovial fluid in rheumatoid arthritis) 
HANNESTAD, K. (1967) Clin. exp. Immunol., 2, 511 (Presence of aggregated $\gamma$ G-globulin in certain rheumatoid synovial effusions)

—_, AND MeLlBYE, O. J. (1967) Ibid., 2, 501 (Rheumatoid factor in synovial effusions: local production and consumption)

KunKel, H. G., Müller-Eberhard, H. J., Fudenberg, H. H., AND Tomasi, T. B. (1961) J. clin. Invest., 40, 117 (Gamma globulin complexes in rheumatoid arthritis and certain other conditions)

LAURELL, C.-B. (1965) Anal. Biochem., 10, 358 (Antigen-antibody crossed electrophoresis)

MacSween, R. N. M., Dalakos, T. G., Jasani, M. K., Boyle, J. A., Buchanan, W. W., and Goudie, R. B. (1968) Clin. exp. Immunol., 3, 17 (A clinicoimmunological study of serum and synovial fluid antinuclear factors in rheumatoid arthritis and other arthritides)

Mellors, R. C., Heimer, R., Corcos, J., AND Korngold, L. (1959) J. exp. Med., 110, 875 (Cellular origin of rheumatoid factor)

MunTHE, E. (1972) Scand. J. Rheum., 1, 161 (Anti-IgG and antinuclear antibodies in juvenile rheumatoid arthritis)

Ploem, J. S. (1967) Z. wiss. Mikr., 68, 129 (The use of a vertical illuminator with interchangeable dichroic mirrors for fluorescence microscopy with incidental light)

RITCHIE, R. F. (1967) Arthr. and Rheum., 10, 544 (The clinical significance of titered antinuclear antibodies)

Ropes, M. V., BenNett, G. A., CoBb, S., JACOX, R., AND JeSSAR, R. A. (1959) Bull. rheum. Dis., 9, 175 (1958 revision of diagnostic criteria for rheumatoid arthritis)

SCHROHENLOHER, R. E. (1966) J. clin. Invest., 45, 501 (Characterization of the $\gamma$-globulin complexes present in certain sera having high titer of anti- $\gamma$-globulin activity)

SveC, K. H., AND VeIT, B. C. (1967) Arthr. and Rheum., 10, 509 (Age-related antinuclear factors: immunologic characteristics and associated clinical aspects)

The, T. H., AND FeltKamP, T. E. W. (1970) Immunology, 18, 865 (Conjugation of fluorescein isothiocyanate to antibodies. I. Experiments on the conditions of conjugation)

WeEKE, B. (1968) Scand. J. clin. Lab. Invest., 22, 107 (Quantitative estimation of human immunoglobulins following carbamylation by electrophoresis in antibody-containing agarose)

WiIK, A., JensEN, E. M., AND FrIIS, J. (1973) Scand. J. Rheum., 2, 9 (Granulocyte-specific antinuclear factors in rheumatoid arthritis sera and synovial fluids)

- AND MUNTHE, E. (1972) Immunology, 23, 53 (Restrictions among heavy and light chain determinants of granulocyte-specific antinuclear factors)

WillKens, R. F., Whitaker, R. R., ANDERSON, R. V., AND BerVen, D. (1967) Ann. rheum. Dis., 26, 306 (Significance of antinuclear factors in older persons)

Winchester, R. J., Agnello, V., AND Kunkel, H. G. (1970) Clin. exp. Immunol., 6, 689 (Gamma-globulin complexes in synovial fluids of patients with rheumatoid arthritis. Partial characterization and relationship to lowered complement levels)

- KunKel, H. G., AND Agnello, V. (1971) J. exp. Med., 134, 286S (Occurrence of $\gamma$-globulin complexes in serum and joint fluid of rheumatoid arthritis patients: use of monoclonal reheumatoid factors as reagents for their demonstration) 